\title{
Artigos
}

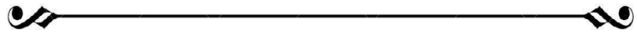

\section{A BENEVOLÊNCIA À PROVA DOS EXCLUÍDOS: RELAÇÕES ENTRE VOLUNTÁRIOS E USUÁRIOS DE UM CENTRO DE SAÚDE HUMANITÁRIO FRANCÊS}

\author{
The benevolence test of the excluded: relations between volunteers \\ and users of a French humanitarian health center
}

\author{
Jaqueline Ferreira*
}

\begin{abstract}
Resumo. O movimento Humanitário assume cada vez mais relevância nos debates atuais sobre direitos humanos, relações internacionais e globalização diante da crescente onda de imigração mundial e o acolhimento dos países de exílio. Este trabalho busca contribuir para essa reflexão apresentando dados de uma etnografia realizada em um centro de atendimento médico da Organização Não Governamental francesa, Medécins du Monde, em Paris. As representações francesas sobre a imigração e exclusão social influenciavam as interações entre voluntários e usuários imigrantes irregulares do centro. A discussão diz respeito à aceitação, expectativas e julgamentos nas interações colocando em questão o ideal da benevolência preconizado pela organização como acolhimento humanitário.
\end{abstract}

Palavras chave: imigração, humanitário, alteridade, assistência.

Abstract. The Humanitarian movement increasingly assumes relevance in the current debates on human rights, international relations and globalization in the face of the growing wave of global immigration and reception of the countries of exile. This paper seeks to contribute to the reflection by presenting data from an ethnography held at a medical center of the French Non-Governmental Organization, Medécins du Monde, in Paris. The French representations on immigration and social exclusion influenced the interactions between volunteers and clandestine immigrant users of the center. The discussion concerns acceptance, expectations and

* Universidade Federal do Rio de Janeiro (IESC/UFRJ). Rio de Janeiro, RJ, Brasil. 
judgments in the interactions, calling into question the ideal of benevolence advocated by the organization as a humanitarian assistance.

Keywords: immigration, humanitarian, alterity, assistance.

Este trabalho apresenta dados de uma etnografia realizada em um centro de atendimento médico de uma Organização Não Governamental (ONG) francesa, nomeada Medécins du Monde (MDM), em Paris ${ }^{1}$. Tal centro foi criado em 1986, após os debates na França sobre a crescente dificuldade de acesso aos serviços de saúde por uma população excluída socialmente. A organização MDM tomou a iniciativa de abrir tal centro de saúde local, com o objetivo de prestar assistência médica, bem como propiciar a inclusão dessas pessoas nas estruturas comuns de acesso aos direitos. Essa iniciativa ficou conhecida como "Missão França", tendo sido concebida em caráter de "urgência" e temporário. No entanto, ela persiste até hoje, mostrando que as questões relativas à exclusão social dos imigrantes e de uma população francesa em precariedade social estão longe de ser resolvidas.

O movimento Humanitário assume cada vez mais relevância nos debates sobre direitos humanos, relações internacionais e globalização. Embora sua ideologia tenha pretensão à universalidade, há diferentes concepções e práticas, de acordo com o contexto de atuação, atores e população alvo. Daí vem a pertinência de estudos etnográficos de missões humanitárias específicas²

Assim, a primeira parte do artigo apresenta uma contextualização do surgimento da organização e de sua atuação junto aos excluídos, enquanto a segunda refere-se ao contexto e interações no centro, a suas vicissitudes e desafios cotidianos. As considerações finais buscam compilar as particularidades do mesmo e as implicações na assistência humanitária aos excluídos.

\section{O nascimento das organizações humanitárias}

Em 1971, Bernard Kouchner e um grupo de médicos participavam de uma missão na Cruz Vermelha, tratando as vítimas da Guerra de Biafra (19671970). Desejando engajar-se politicamente e insatisfeitos com os princípios de neutralidade política da organização, rompem com a mesma e fundam os Médecins sans Frontières (MSF). Mais tarde, em 1980, uma nova dissidência interna dessa ONG faz com que Bernard Kouchner e outro grupo de médicos

\footnotetext{
Trata-se do resultado final do trabalho de conclusão de meu doutoramento (ver FERREIRA, Jaqueline. Soigner les Mal Soignés, Ethnologie d'un centre de soins gratuits).

2 Sobre etnografias em contextos de atuações específicos, ver CENTLIVRES, Pierre, CENTLIVRESDEMONT, Micheline. L'anthropologie face à I'humanitaire. État, Islam et Tribus face aux organisations internationales. Le cas de l'Afghanistan. 1978-1998; SAILLANT, Francine. A Responsabilidade na Intervenção Humanitária: indiferença ou engajamento?; FERREIRA, Jaqueline. O Humanitário no Brasil: entre o ideal universal e a cultura local.
} 
fundem os Médecins du Monde (MDM)3. Apesar da divisão, as duas organizações possuem os mesmos objetivos: tratar doentes e vítimas de guerras, catástrofes, miséria e testemunhar as injustiças, de maneira que a solidariedade não seja limitada por fronteiras internacionais, interesses estatais, imperativos ou diplomático-estratégicos. Dessa maneira, Médecins sans Frontières e Médecins du Monde marcam o nascimento das grandes estruturas humanitárias fundadas exclusivamente por médicos e que se caracterizam pelo envio de pessoal a campo. Elas primam por uma medicina de urgência, na qual a rapidez de ação é fundamental, como também por missões de desenvolvimento dos países pobres, por meio dos princípios da Saúde Pública. O caráter humanitário que anima essas organizações, portanto, compreende toda a ação empreendida para prestar ajuda a qualquer ser humano, sem distinção. De acordo com Ruffin ${ }^{4}$, mesmo que essa conotação englobe a noção de caridade, ela se desenvolve em sentido inverso: enquanto a caridade aceita a ordem das coisas, o Humanitário visa a transformá-la, o que termina por aliá-lo ao projeto político e social.

As segmentações sucessivas que marcaram a história e a produção desse novo discurso do Humanitário trouxeram a perspectiva do que constitui a boa intervenção: o reconhecimento de certas populações como vulneráveis aos problemas que ultrapassam o domínio do simples registro médico para o âmbito dos direitos humanos ${ }^{5}$.

\section{O acesso à saúde na França: um affaire humanitário}

Nos anos 80, a França assiste a uma mudança de seu discurso sobre a pobreza. Se nos anos 60 a pobreza era uma condição transmitida de geração a geração, nesse momento, ela passa a atingir a população de forma massiva, com crescente desemprego. A noção de "exclusão social" é então introduzida por René Lenoir ${ }^{6}$, e explica a vulnerabilidade social pela interdependência ininterrupta entre diferentes variáveis. A renda não é mais o critério principal para definir os excluídos, mas sim quatro domínios são levados em conta: habitação (mal-logés, sans domicilie fixe); emprego (desempregados de longa data); escola (acesso ao ensino, fracasso escolar); saúde (acesso à assistência médica).

\footnotetext{
KOUCHNER, Bernard. L'Ile de Lumière.

RUFFIN, Jean-Christophe. Le Pitiè Humanitaire.

O Humanitário tem sido documentado por vários militantes e pesquisadores, desde seu surgimento. O nascimento de MSF e MDM está relatado em Kouchner (op. cit.). Ruffin (op. cit.) faz uma análise histórica das ideologias que animam essas organizações.Uma breve história do nascimento dessas organizações para o público brasileiro está disponível em FERREIRA, Jaqueline. O Humanitário: uma história de ideologias e práticas face às populações vulneráveis. Para análises mais recentes do Humanitário, ver FASSIN, Didier, PANDOLFI, Mariella. Contemporary States of Emergency. The politics of military and humanitarian interventions; FASSIN, Didier. La Raison Humanitaire: une histoire morale du temps present.

6 LENOIR, René. Les exclus. Un Français sur dix.
} 
Paralelamente, a crise do Estado Providência conduz a uma mudança da mentalidade em relação à solidariedade: a negociação de um novo contrato social deve encontrar uma saída para as dificuldades, com o recurso do setor privado e associações ${ }^{7}$. É assim que o Humanitário, até então destinado a socorrer populações de terceiro mundo, volta-se para a Europa. Os engajamentos voluntários e as doações públicas são amplamente encorajados. Enquanto os trabalhadores sociais transmitem a imagem de uma enorme burocracia, contribuindo para o sofrimento e perpetuação da vulnerabilidade social, o voluntariado perde a imagem arcaica de "obras caridosas", para incorporar a imagem de cidadãos engajados. A solidariedade busca renovar-se com os valores humanitários.

Dessa maneira, as associações humanitárias tiveram um importante papel na França no que se refere à revelação dos processos de exclusão e na busca de soluções apropriadas para a situação. Elas entraram na cena social, com o desejo de ter sua expertise reconhecida, interpelando os poderes públicos, por meio de ações amplamente midiatizadas. Nesse contexto, foi criado o primeiro centro MDM em Paris, em $1987^{\circ}$.

Por meio da Primeira Conferência de Imprensa, de 18 de dezembro de 1986, que tratava do estudo de 1.106 casos dos pacientes recebidos, comprovou-se que uma parcela significativa da população que vivia na França tinha dificuldade de acesso à assistência médica e, portanto, a necessidade de uma missão humanitária no país ${ }^{9}$. Durante os três primeiros anos, MDM se engaja em ações precisas e nas reflexões sobre o acesso à saúde, com grande apoio da mídia e de personalidades francesas importantes. A visita, em 1988, do presidente da república, François Mitterand, e a nomeação de Bernard Kouchner, fundador de MDM e MSF, ao governo são consideradas vitórias do movimento humanitário na França.

MDM, igualmente, está intimamente associado à criação de dispositivos legais que melhoraram a situação da exclusão social na França, como, por exemplo, o Revenu Minimum d'Insertion (RMI ${ }^{10}$. No entanto, a população de nacionalidade estrangeira que vive na França continuou excluída dos cuidados médicos.

\footnotetext{
ROSANVALLON, Pierre. La Crise de l'État Providence.

8 Autores que retratam o nascimento dessa missão com detalhes são MESTIRI, Ezzedine. Au Dispensaire de Médecins du Monde à Paris; MESSU, Michel. Pauvreté et Exclusion en France; MAMOU, Jacky. Entre action humanitaire et solidarité citoyenne: I'exemple de la Mission France de Médecins du Monde.

9 GOURIOU, J. Rapport d'Enquete sur la Mission France.

${ }^{10}$ O RMI, ou Renda Mínima de Inclusão Social, é um contrato que proporciona auxílio mensal e acesso às estruturas de assistência a pessoas que vivem em exclusão social, mediante o compromisso de engajamento em alguma formação profissional, de forma a levá-las a uma inclusão social a médio prazo.
} 
A França contou com a participação de trabalhadores estrangeiros em toda sua história industrial, e os principais contingentes imigratórios estão relacionados aos períodos de reconstrução, que se seguiram às duas grandes guerras mundiais e ao boom econômico dos anos 1960. Assim, o imigrante foi visto como mão de obra importante até a década de 1970. Entretanto, a recessão econômica e as cotizações sociais fizeram nascer os argumentos de que eles mais oneravam do que contribuíam e que sua presença em território nacional retardava a modernização de vários setores da economia. A opinião pública passou a considerá-los uma ameaça à identidade nacional, à homogeneidade cultural e à democracia. Consequentemente, a partir dos anos 70, todos os governos europeus decidiram refrear a imigração, limitando-a às famílias dos indivíduos estrangeiros já instalados em território nacional, exilados políticos, estudantes, trabalhadores sazonais e aos cidadãos da comunidade europeia. Em outros termos, com a perda do valor econômico, a imigração tornou-se indesejável.

Esse processo desencadeou políticas públicas que produziram leis para reprimir a imigração estabelecendo um regime de expulsão e a restrição da regularização de vistos. A lei Pasqua, de 1993, por exemplo, estabeleceu que nenhuma prestação social deveria ser concedida aos estrangeiros em situação de irregularidade, o que levou ao controle dos vistos em locais públicos, até mesmo nos hospitais ${ }^{11}$. Isso acarretou o engajamento da MDM na luta pela garantia do direito à assistência médica desses indivíduos, sem que esses corressem risco de ser presos ou expulsos do país. O resultado desse empreendimento concretizou-se em janeiro de 2000, com a implantação da Couverture Maladie Universelle (CMU) e Aide Médicale d'État Rénovée (AMER).

A CMU estabelece um direito com base na assistência social francesa (Securité Sociale) a todo estrangeiro residente no país em situação estável e regular, independentemente de ele possuir trabalho ou não. Ela oferece igualmente complemento de renda às pessoas que vivem em situação precária, direito similar ao fornecido aos franceses beneficiários do RMI. A lei prevê também assistência médica e hospitalar e acesso gratuito a medicamentos.

A AMER favorece o acesso à saúde aos estrangeiros em situação de irregularidade administrativa, ou seja, sem visto de estadia e cujos recursos monetários são insuficientes. O estrangeiro que deseja se beneficiar da AMER deve residir no país há mais de três meses (excluindo-se assim os "turistas") ou simplesmente manifestar desejo de permanecer na França. A maioria dos usuários do centro (70\%) atendia aos critérios para obtenção da AMER, e pequena porcentagem (10\%) é de turistas, que não têm direito a nenhum benefício social francês ${ }^{12}$.

\footnotetext{
${ }^{11}$ FASSIN, Didier, MORICE, Alain. Les épreuves de l'irrégularité: les sans-papiers, entre déni d'existence et reconquête d'un statut.

12 Document MDM. Rapport d'Activité de la Mission France, 2000.
} 


\section{O centro de saúde MDM como espaço de observação}

Esta pesquisa contou com o exercício de observação participante das interações entre voluntários e usuários do centro da MDM, em seus diferentes espaços (recepção, sala de espera, sala de enfermagem e consultas médicas), durante dois anos (2000-2002), com frequência de duas a três vezes por semana, em dias alternados. Conversas informais com voluntários e usuários, relatórios, dossiês médicos e sociais também foram fontes de dados ${ }^{13}$. Dessa forma, optei pela 'produção' dos dados, elaborando uma pesquisa de longa duração ${ }^{14}$. Assim, foi possível, além de ampliar contatos, multiplicar as situações de observação e observar diferentes espaços e situações por longo tempo, analisando as regularidades e particularidades das interações. Da mesma maneira, foi possível estabelecer contato mais próximo com os voluntários e usuários, uma relação de maior proximidade, e contextualizar no tempo como a criação de novos dispositivos e leis relativos à imigração e à exclusão social no país influenciaram essas interações.

No momento da pesquisa, o centro contava com o trabalho voluntário de profissionais da saúde (médicos, enfermeiros, dentistas) e trabalhadores sociais (assistentes sociais, funcionários públicos). Durante o trabalho de campo, acompanhei mais precisamente 15 voluntários que se ocupavam da assistência social e de 24 profissionais de saúde, médicos em sua maioria. Eles compunham um grupo diversificado de pessoas pertencentes a diferentes classes sociais, idades e formações profissionais e com diferentes motivações para o trabalho voluntário. Esse perfil dos voluntários confirma os estudos já realizados sobre o assunto: a forte heterogeneidade dos atores engajados no seio das organizações humanitárias ${ }^{15}$.

A população recebida era composta, em sua maioria (80\%), por imigrantes africanos que viviam em situação irregular, os sans papiers, originários de Máli, Costa do Marfim, Congo, Senegal. Uma pequena parcela era representada por franceses moradores de rua e desempregados em fase final do auxílio desemprego ${ }^{16}$.

O processo de trabalho no centro consistia na recepção dos pacientes em um guichê, onde eles eram identificados pelos voluntários. Após, eles

\footnotetext{
${ }^{13}$ Os dossiês médicos e sociais do centro da MDM correspondem a prontuários dos usuários que contêm informações sobre sua situação clínica e socioeconômica, respectivamente.

${ }^{14}$ É impossível desenvolver neste espaço todas as nuanças dessa etnografia. O fato de ser médica me permitiu observar as consultas médicas, e foi desenvolvido em FERREIRA, Jaqueline. A Consulta Médica como Drama Social - um olhar etnográfico. A expressão 'produção de dados' é utilizada aqui na perspectiva de Olivier de Sardan (OLIVIER DE SARDAN, Jean-Pierre. La Politique du Terrain), e diz respeito aos dados que são produzidos pela combinação de diferentes fontes, os quais se tornam construção pessoal do pesquisador.

15 DAUVIN, Pascal, SIMÉANT, Johanna. Le travail humanitaire. Les acteurs des ONG, du siège au terrain.

${ }^{16}$ Documento MDM, op. cit.
} 
eram encaminhados para a sala contígua, a sala de espera, e aguardavam o atendimento do acolhimento social, onde havia outros voluntários preparados para entrevistá-los. Após isso, eles eram encaminhados aos cuidados de enfermagem ou consulta médica.

O foco desse artigo é o acolhimento social do referido centro, espaço destinado a coletar os dados da população recebida, acolher suas demandas de diferentes ordens e dar os possíveis encaminhamentos. Pretendo mostrar como o contexto francês no momento da pesquisa, ou seja, as representações sobre a imigração e exclusão social, terminavam por influenciar as interações entre voluntários e usuários do centro. O interesse aqui se volta para o acolhimento, as expectativas e os julgamentos sobre as situações, tanto da parte dos voluntários como dos usuários, colocando em questão o ideal da benevolência compreendida no que era preconizado pelo centro MDM como acolhimento humanitário.

\section{Acolhimento social: os direitos à prova dos excluídos}

A ignorância dos direitos pelas pessoas atendidas pelos trabalhadores sociais é surpreendente! (voluntário)

Todo o trabalho social era constituído pela articulação entre os documentos, os discursos e as práticas. As atividades primordiais desenvolvidas pelos voluntários nesse espaço eram: preencher o dossier social, atender às necessidades imediatas (encontrar alojamento, fornecer os endereços de refeitórios gratuitos, banhos públicos) e informar aos usuários seus direitos e os meios para aceder a eles. Eram tarefas aparentemente simples, mas que podiam empreender uma jornada inteira.

Os dados do dossiê social eram muito valorizados, pois eles alimentavam as estatísticas sobre as ações da missão. Por outro lado, seu preenchimento era um momento privilegiado para o estabelecimento de trocas com os usuários e a identificação de como a assistência humanitária poderia ser justificada e mais eficaz.

As informações colhidas diziam respeito à identificação: data de nascimento, sexo, nacionalidade, data de entrada na França, alojamento, estado civil, número de filhos; e também a dados sociais: período de residência na França, documentos de identidade, visto de entrada, recursos financeiros, trabalho. Igualmente, figuravam aí as dificuldades encontradas para o acesso aos direitos, obstáculos de ordem econômica, administrativa, funcional e cultural. Essas informações eram coletadas objetivamente, de modo a uniformizar os dados e torná-los acessíveis à pluralidade dos voluntários. As informações complementares e impressões pessoais eram anotadas à margem. Todas as informações contidas no dossiê social circulavam no interior do centro e ajudavam a estabelecer os julgamentos e serviam de referência aos voluntários. 
Autores como Michèle Grosjean e Michèle Lacoste ${ }^{17}$ já observaram como a produção escrita obtida nos preenchimentos dos dossiês sociais hospitalares apresenta papel cognitivo e contém aspectos subjetivos, apesar da suposta aura de objetividade que a norteia. Isso vai ao encontro da perspectiva desse artigo que sublinha a análise de como o preenchimento do dossiê social correspondia a uma competência específica e os dados coletados traduziam as expectativas e a expertise do centro. Um exemplo importante era a importância dada à questão sobre a vontade de permanecer ou não no país, tendo em vista o acesso ou não à lei AMER.

O acolhimento social não tinha uma divisão física da sala de espera, e assim o preenchimento social se dava aos olhos de todos, com pouca privacidade. Voluntários e usuários tentavam gerir essa situação, falando em voz baixa. Era uma limitação que explicava em parte porque os usuários evitavam "contar tudo". Por outro lado, os usuários da sala de espera tinham a possibilidade de observar essas interações, o que lhes propiciava apropriar-se das técnicas de "apresentação de $\mathrm{si}^{\prime \prime}$, que permitiriam se beneficiarem das prestações do centro $^{18}$.

De fato, mesmo que os voluntários fossem receptivos, os usuários frequentemente se sentiam intimidados por todas essas etapas administrativas, que tornam públicas uma parte da vida privada. Isabelle Astier ${ }^{19}$ já havia observado como as "biografias administrativas" para obtenção do Revenu Minimum d'Insertion dão origem a um sentimento de "vasto empreendimento de exploração da intimidade dos beneficiários". O mesmo podia se verificar ao centro, à medida que esse momento era o da escuta privilegiada, de trocas, desabafos, dúvidas, angústias, confidências que são colocadas em cena pelo usuário e pelos voluntários.

\section{Aceitar ajudar}

Pode ser que meu temperamento não corresponda à demanda que existe atualmente. (voluntária)

As orientações sobre os direitos inscreviam-se em um quadro complexo: implicavam conhecimento e acesso a leis, direitos e dispositivos e determinadas competências relacionais para uma boa interação com os usuários. Na visão dos voluntários, a maioria dos usuários não tinha conhecimento de seus direitos nem de como acessá-los. Igualmente relevante era a não-fluência na língua francesa, tornando difícil a compreensão de informações, burocracias e da

\footnotetext{
17 GROSJEAN, Michèle, LACOSTE, Michèle. L'oral et l'écrit dans les communications de travail ou les illusions du tout écrit.

${ }^{18}$ Como lembra Erving Goffman, em "Apresentação de si" em sua obra A Representação do Eu na Vida Cotidiana, sobre as representações interacionais entre indivíduos ocupando posições de desigualdade.

${ }^{19}$ ASTIER, Isabelle. Se raconteur aux Autres.
} 
linguagem administrativa. Assim, era primordial para os voluntários estar bem informados para saber aconselhar e, ao mesmo tempo, estabelecer um clima de confiança para uma boa interação com os usuários.

A assistência oferecida pelo centro era organizada de acordo com a possibilidade ou não de aceder aos direitos de acesso aos serviços de saúde. Esse elemento era determinante na relação que se estabeleceria entre usuários e voluntários. No entanto, o trabalho voluntário do centro, apesar de se orientar pelas prerrogativas da organização, expressava igualmente representações mais amplas da sociedade francesa sobre a exclusão social e imigração. Nesse sentido, as representações sobre a imigração da sociedade francesa e a implantação das leis Couverture Maladie Universel (CMU) e Aide Médicale Rénovée (AMER) foram exemplares desse aspecto.

Conforme referido, $80 \%$ das pessoas recebidas no centro eram imigrantes em situação irregular. Grande parte delas possuía direito à AMER, isto é, estavam na França há mais de três meses irregularmente e desejavam permanecer no país. O trabalho dos voluntários, nesse caso, consistia em informá-los sobre esse direito e auxiliá-los nas formas de aceder-lhe. Essa lei gerava polêmicas no centro. Os voluntários se questionavam continuamente sobre ela, pois, segundo eles, poderia gerar um afluxo desmesurado de imigrantes. De acordo com sua experiência, mesmo que a lei fosse desconhecida da maioria dos imigrantes, uma parcela significativa emigrava para a França, na expectativa de obter tratamentos médicos em função dela, o que fatalmente culminaria em problemas sociais. O relato de um voluntário foi significativo:
A AMER mudou tudo. Hoje, as pessoas vêm à França só por causa da AMER, porque eles sabem que têm direitos, se eles disserem que desejam ficar aqui. As pessoas aprendem o discurso. Quando qualquer coisa thes é negada, eles mudam imediatamente o discurso. Isso vai trazer um problema político a longo prazo.

Da mesma forma, os voluntários identificavam uma expectativa por parte dos imigrantes de que a AMER fosse um passo em direção à obtenção do visto de permanência definitiva no país: "Porque está marcado Auxílio Médico do Estado. Do ESTADO, você entende? Isso faz um efeito na cabeça das pessoas", referiu um voluntário.

Assim, mesmo que esses voluntários se apoiassem na prerrogativa do centro de que era dever do Estado francês acolher esses imigrantes, havia igualmente a ideia de que essa imigração excessiva poderia sobrecarregá-lo e criar a dependência desses indivíduos ao Estado. É tentador lembrar aqui as noções sobre a pobreza do século XIX, em relação ao caráter político da assistência, onde qualquer ajuda estatal poderia igualmente criar a dependência ao Estado ${ }^{20}$.

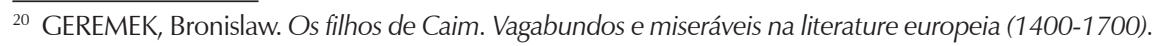


Todavia, todas as reflexões relativas à imigração e exclusão social não implicavam colocar em questão a jurisdição dos direitos adquiridos pelos usuários. Por exemplo, Thèrese, uma voluntária, ajudou Nicolas, morador de rua, a obter o Revenu Minimum d'Insertion (RMI), mesmo sabendo que seus problemas neurológicos decorrentes do alcoolismo não lhe dariam condições mínimas de reinserção social a longo prazo, conforme previsto na lei. Assim, ela questionava, com certa ironia: "Imagine uma pessoa como Nicolas com RMI!".

Havia, portanto, uma constante construção de relações com o Outro, de acordo com a perspectiva dos direitos a que esses indivíduos tinham acesso. Segundo essa voluntária:

Antes, a grande maioria eram franceses, moradores de rua. Muitos alcoólicos. Eu ajudei dois a conseguir a aposentadoria. Eu tenho a impressão de que houve uma época em que realmente podíamos fazer algo, ajudar de muitas formas. Eram franceses e, portanto, tinham direitos, enquanto, agora, são sobretudo imigrantes clandestinos... Como é que você pode ajudar um deles a obter a aposentadoria? É impossível, ou seja, atualmente, há situações em que não se pode fazer nada. Pode ser que meu temperamento não corresponda à demanda que existe agora.

Esse relato é ilustrativo de como a aceitação ou não dos usuários repousa sobre a visão do trabalho de voluntariado exercido a título humanitário. De fato, o humanitário assumia uma forma particular para esses voluntários: a disposição era favorável, segundo a possibilidade de ajudar os usuários. A relação com os imigrantes, portanto, era sempre associada a um sentimento de impotência devido ao fato de que as respostas legislativas à situação presente serem insuficientes. Isso originava frustração, que repercutia em dificuldade na interação com os imigrantes enquanto as relações com os franceses eram mais confortáveis: "O contato é mais fácil". Uma voluntária observou: "Eu estou de acordo que não se pode abandonar essas pessoas. É preciso lhes tratar e tentar ajudá-las. Mas será que é possível ajudá-las verdadeiramente? Você pode lhes achar um alojamento por dois dias, mas e depois?".

Eis um exemplo sobre como a impossibilidade de ajuda humanitária gerava frustração nos voluntários: um jovem chinês foi encaminhado ao centro por alguém que o encontrou na rua, sozinho, sem ter o que comer, onde dormir e sem saber falar francês. Ele possuía um documento indicando uma hora marcada em dois meses, para um pedido de asilo. Apesar do descontentamento evidente dos voluntários, pois, "quando eles não sabem o que fazer, trazem para Médecins du Monde", todos os esforços possíveis foram empregados para lhe encontrar alojamento. Finalmente, foi encontrado um local em um alojamento em Nanterre, subúrbio parisiense, e providenciado dinheiro para o transporte até o local. Alguns dias mais tarde, os voluntários tentaram obter notícias do jovem chinês junto aos funcionários do alojamento em Nanterre, 
mas uma má notícia lhes esperava: ele nunca esteve lá. O desalento foi geral. A voluntária que se encarregou do caso comentou a situação:

Você vê: um jovem chinês que não fala francês, que o colocaram na rua para fazer um pedido de asilo político... o que você quer que façamos? Não sabemos onde ele está agora, provavelmente, na rua. Esse jovem chinês que poderíamos recuperar vai provavelmente trabalhar em uma rede de trabalhos clandestinos, não sei... Você vê? Tentamos fazer algo. Eu acho isso dramático. O que podemos fazer por todas essas pessoas que chegam e que querem ficar na França e que nunca vão receber um visto de estada?

O fracasso dos esforços empregados, bem como a recusa de uma ajuda real e concreta, esvaziava o sentido da atividade voluntária. Adam Smith ${ }^{21}$ já havia chamado a atenção sobre como o mérito de uma ação dirigida ao Outro se dá na forma simbólica do reconhecimento e simpatia em relação à pessoa que realiza a ação. Podemos nos perguntar se o que inquietava os voluntários seria somente a limitação da ajuda humanitária ou igualmente a impossibilidade do reconhecimento dos esforços de intervenção em favor do Outro.

\section{A recusa de ajuda}

O problema é que se preocupam demais comigo. Isso não me agrada. Eu gostaria que me deixassem em paz. (morador de rua)

Em muitas ocasiões, a possibilidade de realizar ajuda concreta a certos usuários esbarrava em recusas por medo, desconfiança ou desinteresse no que estava sendo proposto. O autor dessa epígrafe, por exemplo, era um morador de rua, acompanhado pelos psiquiatras do centro. A frase acima foi evocada durante uma discussão com um voluntário, pois ele não queria um alojamento que estava lhe sendo proposto: "Eu não sou deficiente, eu posso me virar sozinho". Todavia, o trabalho humanitário só teria sentido diante da possibilidade desse acompanhamento, em que todos os recursos possíveis eram colocados à disposição dos usuários de maneira enérgica. Assim, esse tipo de recusa gerava frustração nos voluntários. Isso ficava mais claro, quando os imigrantes sans papiers tinham a possibilidade de acesso à AMER, mas a recusavam.

A observação do acolhimento social mostrava como era frequente ver um voluntário explicar sistematicamente a todos os pacientes imigrantes como eles tinham direito à AMER: "Assim, vocês não precisarão mais vir aqui. Não precisa ser regularizado. Um certificado de quem Ihes dá alojamento é suficiente". Um modelo de certificado era entregue. Muitos mal-entendidos e dúvidas decorriam dessas informações: quem os aloja também estava irregular, aceitaria ele preencher o certificado? Outros devolviam o certificado, pois eles vieram consultar o médico e isso não lhes interessava. Diante dessa recusa, os

\footnotetext{
${ }^{21} \mathrm{SMITH}$, Adam. Théorie des sentiments moraux.
} 
voluntários reagiam com hostilidade: "Se você não quer seus direitos, eu não posso fazer nada por você".

Segundo essa lógica, havia um estranhamento em relação às atitudes de passividade dos usuários. Segundo as recomendações do centro, era necessário que esses usuários adquirissem consciência de seus direitos: "É preciso lhes ajudar a reagir", repetia a coordenadora do centro, mostrando que a atitude de passividade por parte dos usuários não era bem aceita, como ilustra a fala de uma voluntária:

Há pessoas que buscam várias coisas de que realmente necessitam. No entanto, há outras que não têm nenhuma demanda, a não ser o tratamento. E isto é um verdadeiro problema para quem recebe essas pessoas: avaliar se é possível ou não propor alguma coisa, pois quando se faz o dossiê se descobrem coisas que podemos lhes propor.

Dessa forma, a atividade dos voluntários sempre entrava em conflito com o indivíduo jurídico pleno de direitos e o indivíduo real e complexo.

\section{Transmitir confiança}

Se eu disser que quero ficar na França, sou atendida, não é? (usuária imigrante)

Os imigrantes em situação administrativa irregular no país, conforme já referido, apresentavam reações de desconfiança e temor em relação às instituições francesas, dentre elas, os serviços de saúde. O receio de serem denunciados pela instituição fazia com que as relações deles com esses serviços fossem estabelecidas com muitas precauções. Essa desconfiança aplicava-se igualmente ao centro MDM.

Conforme relatado, as questões rotineiras dos voluntários do centro, como: "Você está na França há quanto tempo?", "Você tem documento de identidade?", eram particularmente mal recebidas. Abdelmalek Sayad ${ }^{22}$ realizou estudos clássicos sobre a questão da imigração na França e observou como a desconfiança do imigrante em relação à medicina e à Securité Sociale era reflexo das relações que ele estabelece com a sociedade francesa. Assim, o sentimento constante de ser objeto de acusação não era somente devido a uma relação difícil ou a algum conflito com essas instituições, mas se inscrevia em um contexto mais amplo e mais constante da vida quotidiana. Isso é particularmente verdadeiro no trabalho do centro, cujas biografias administrativas são o eixo central do trabalho.

Para atenuar essas reações, os voluntários do centro procuravam estabelecer uma "relação de confiança" com os imigrantes. Na entrada do centro, por exemplo, podia-se ver um cartaz dizendo: "Para melhor ajudar e

${ }^{22}$ SAYAD, Abdelmalek. La double absence: des illusions de l'immigré aux souffrances de l'immigré. 
atender, por favor, responda da melhor maneira possível às nossas questões. Essas informações permanecerão confidenciais". Assim, os voluntários tentavam fazê-los compreender que o centro assegurava o caráter confidencial dos dados. Eles atuavam como conselheiros e, dessa forma, valorizavam sua própria capacidade de aceder à confiança dos usuários. Enfim, a fim de assegurar a efetividade da ação humanitária, era importante que a relação de confiança fosse estabelecida. Na maioria dos casos, entre usuários e voluntários essa relação de confiança conseguia ser estabelecida, conforme demonstra o relato desta voluntária:

A dificuldade são as pessoas que dão falsas informações, que desconfiam. Assim, no princípio, elas dão informações falsas, mas em seguida se estabelece uma confiança entre nós, e no final elas confessam que tudo que haviam dito era mentira. É porque eles têm medo, e isso é perfeitamente compreensível, no seu lugar, eu faria a mesma coisa. Eles temem ser presos pela polícia, porque não têm documentos. Então, temos de insistir, dizer que Médecins du Monde é confidencial, e, depois que a relação se estabelece, tudo muda. E finalmente, quando fazemos seu dossiê social, eles nos contam muitas coisas. Eu os deixo falar, eles têm necessidade de falar.

O relato dessa voluntária mostra outra situação, na qual eles eram continuamente confrontados: a mentira. O recurso da mentira era uma maneira de os imigrantes reverterem a situação a seu favor, modificando os sinais que poderiam ser suscetíveis ao julgamento do outro. Nesses casos, não se tratava de uma situação de enganar, mas de colocar o outro à distância, de lhe impedir o acesso a dados que poderiam lhe colocar em perigo. Por outro lado, a exposição do sofrimento era necessária, a fim de convencer o interlocutor da real necessidade de ajuda. Assim, era preciso saber julgar o que devia ser dito e o que devia ser ocultado. Diante disso, em muitas ocasiões, os imigrantes eram flagrados em contradições pouco propícias a uma demanda de ajuda. O exemplo mais frequente era o pedido do certificado de alojamento para aceder à AMER. O constrangimento dos imigrantes sobre essa questão se traduzia em hesitações, em que os voluntários tentavam lhes tranquilizar: "Reflita e me diga da próxima vez".

Nesses casos, a mentira era parte integrante das relações, em que um sabe que o outro mente e o outro sabe que o primeiro sabe que ele mente. Apesar dos voluntários reconhecerem as razões e a legitimidade das mentiras dos imigrantes, isso não impedia que os conflitos e acusações recíprocas fossem frequentes. O exemplo a seguir é ilustrativo: um homem argelino, procurando uma consulta com o dentista, respondeu à questão sobre a data de sua chegada na França com informação que não coincidia com a data que constava no seu dossier social. Isso gerava uma discussão com o voluntário: Homem argelino: 
"Eu não minto!". Voluntário: "Eu não faço anotações falsas". O homem se irritou e foi embora.

Eu também fui confrontada com a mentira, quando comentei com um voluntário que um imigrante havia me dito que era médico na Argélia: "E você acreditou?", perguntou-me ele. Na verdade, eu não havia pensado na possibilidade de essa informação ser falsa. Mais do que buscar essa veracidade ou não dos fatos, cabe aqui nos interrogarmos sobre o que caracteriza os discursos dos entrevistados em sua relação com a verdade e a mentira na perspectiva antropológica. Trabalhando sobre a mentira na consulta médica, Fainzang 23 já havia observado a necessidade de integrar a mentira como dado à medida que ela se torna produto de um discurso sobre o que é possível dissimular ou inventar.

Em relação ao centro, é importante considerar que as interações entre voluntários e imigrantes se estabeleciam entre indivíduos com diferentes estatutos sociais, e uma relação hierárquica era inevitável. Poder/saber estão imbricados em todas as instâncias da vida social, como bem lembra Michel Foucault ${ }^{24}$. No caso do centro MDM, essa relação de poder não era unívoca, mas sim uma relação de força entre os dois polos, isto é, a posição de saber/ poder do voluntário, que era vivida de maneira ambígua, uma vez que ele "sabe", mas questiona, e o outro que "não sabe", mas dá as respostas necessárias ao exercício desse poder. Assim, se a situação do voluntário promovia o desencadeamento do discurso, o usuário imprimia o tom desse discurso.

Dessa forma, os conflitos eclodiam em razão de os voluntários sentirem-se manipulados. A relação humanitária ideal é aquela em que os usuários apresentam um relato verossímil, mostrando seu reconhecimento aos esforços empregados pelos voluntários em seu favor. Assim, a confiança era uma forma de "pagamento" do trabalho voluntário, um pagamento que não poderia ser outro que não simbólico.

\section{A expressão do conflito}

Não se pode esperar nada de Médecins du Monde. (usuário imigrante)

Os estudos clássicos e contemporâneos realizados em organizações humanitárias, tais como Médecins du Monde, buscam enfatizar o vínculo que se estabelece entre voluntários e usuários $^{25}$. De fato, na maior parte das vezes,

${ }^{23}$ FAINZANG, Sylvie. La Relation médecins/malades: information et mensonge.

${ }^{24}$ FOUCAULT, Michel. Microfísica do Poder.

25 PAUGAM, Serge, PARIZOT, Isabelle, DAMON, Julien, FIRDION, Jean-Marie. La relation humanitaire. La mission France de médecins du monde à Paris; PARIZOT, Isabelle. Soigner les exclus. Identités et rapports sociaux dans les centres de soins gratuits; PARIZOT, Isabelle, CHAUVIN, Pierre, PAUGAM, Serge. The Moral Career of Poor Patients in Free Clinics. 
as relações entre voluntários e usuários eram amistosas. No entanto, o estudo etnográfico no local mostrou que tensões explícitas ou latentes entre eles eram igualmente frequentes. Eu me atenho a dois aspectos, especialmente: primeiro, a maneira como o conflito era expresso por agressões físicas ou verbais e, segundo, pelas reações concretas e as emoções que ele desencadeava.

As manifestações agressivas sob forma de expressão verbal: insultos, ameaças, expressões de descontentamento, podiam ser dirigidas contra a organização, como a do usuário autor da epígrafe acima. Mas eram mais frequentes insultos dirigidos aos voluntários. Segundo uma voluntária: “Um homem da Europa do Leste veio ao MDM logo que chegou em Paris, brigou comigo, me chamou de 'vadia'. Não falava uma palavra em francês, mas isso ele aprendeu rápido". Os motivos de conflito eram de todas as ordens: impossibilidade de acesso à consulta, término de fichas diárias, negação de demandas de outra natureza. Eram eventos que desencadeavam igualmente desabafos para expressar a amargura dos infortúnios quotidianos: "Não se tem direito a nada", dizia uma imigrante da Costa do Marfim, em prantos.

Os gritos dos usuários provocavam reação imediata da parte dos voluntários: eles tentavam gerir a crise, falando em voz baixa, ou buscando ajuda da coordenação, ou outros voluntários. Essa urgência em aplacar a crise tinha como objetivo evitar o desencadeamento de expressões de raiva partindo de outros usuários, tornando a situação difícil de gerir: um conjunto de pessoas gritando e até mesmo partindo para agressões físicas. É importante observar aqui que emoções como a raiva não são incontroláveis, mas sim constituintes de negociações em relações sociais específicas ${ }^{26}$. No caso do centro, tal expressão adquiria sentido, tratando-se de um espaço legítimo para protestos e reivindicações.

As agressões físicas que aconteciam, igualmente não podem ser compreendidas como simples reação visceral. Os voluntários costumavam narrá-las reconstituindo todo o cenário. Havia uma espécie de orgulho naqueles que tinham conseguido gerir uma situação que tinha saído do controle: Nádia, uma voluntária, interveio no momento em que David, um morador de rua, tentou estrangular um usuário. Em outra ocasião, David impediu outro morador de rua de agredir a voluntária Thérese. Enfim, a violência era um fato que atingia todos: voluntários, usuários e pesquisadora. Um dia, Thérese se dirigiu a mim exasperada: "Você tem alguma autoridade sobre David?". David havia saído de seu estado de inércia alcoólica e queria agredir os voluntários.

Em outra ocasião, Medih, outro morador de rua, chutou as cadeiras da sala de espera, porque os voluntários se recusavam a fazer fotocópias de seus papéis: "Nunca mais quero falar com ninguém de MDM", esbravejava ele. Enquanto isso, Marc, um voluntário me falava tranquilamente: "Não é a

${ }^{26}$ BARCELLOS REZANDE, Cláudia, PEREIRA COELHO, Maria Cláudia. Antropologia das emoções. 
primeira vez, mas ele não é agressivo. Têm alguns que trazem facas. Às vezes, precisamos chamar a polícia". É importante observar a tolerância que existia em relação aos moradores de rua, os habitués ${ }^{27}$. Mesmo que Medih estivesse descontrolado e chutando cadeiras, Marc não o considerava "agressivo", pois nunca agrediu fisicamente ninguém e, após esses episódios, voltava ao comportamento amistoso. Assim, não era raro que após episódios como esse as atividades retornassem ao normal.

O sofrimento dos usuários que viviam excluídos socialmente tendia a opacificar o sofrimento dos voluntários, entretanto, este não é menos legítimo. Dentre as experiências emocionais pelas quais os voluntários passavam, o medo ocupava lugar preponderante e influía nas interações do centro. Uma ex-voluntária em visita ao centro relatou:

Eu não lamento nada do trabalho que fiz no MDM, mas é uma experiência que eu não repetiria jamais. Ela deixa marcas. O pior para nós é a violência. Até hoje, se um morador de rua se aproxima de mim no metrô, me pedindo cigarro, eu levo um susto.

Essas emoções geradas pelos conflitos devem ser igualmente compreendidas na perspectiva do jogo de alteridades que diferem de acordo com a pessoa que fala e o contexto no qual ela fala. É importante precisar que o conflito, tal como é tratado aqui, era uma experiência construída nas relações resultantes de um julgamento sobre determinadas situações.

\section{Considerações finais}

A observação cotidiana permitiu vislumbrar que, embora relações acolhedoras e amistosas entre voluntários e usuários, compreendidas no âmbito de uma "relação humanitária", fossem correntes no centro, reações como desconfiança, conflitos e frustração também estavam presentes, colocando à prova a benevolência dos voluntários. Da mesma forma, julgamentos em relação à prestação da ajuda eram frequentes. Esses julgamentos reproduziam as representações sociais vigentes na sociedade francesa, em relação à imigração e à exclusão social.

A capacidade de ajudar dependia de uma boa avaliação do problema por parte dos voluntários. Muitas vezes, mesmo se eles fossem sensíveis à situação das pessoas vivendo em precariedade e sofrimento, esses últimos desconfiavam de todas as etapas administrativas para o acesso aos direitos e à assistência dos serviços de saúde.

\footnotetext{
${ }^{27}$ Os aspectos específicos sobre o acolhimento aos moradores de rua, os sans domicile fixe, foram desenvolvidos em FERREIRA, Jaqueline. Tratar, Cuidar: valores e práticas terapêuticas na assistência humanitária ao sans domicile fixe.
} 
A dificuldade de acesso aos serviços de saúde das pessoas vivendo em exclusão social coloca em questão o respeito aos direitos humanos na sociedade francesa. Como articular os direitos reconhecidos a todos em uma sociedade democrática, e com os entraves institucionais que impedem esse acesso? Os testemunhos dos usuários mostram que esses entraves, aliados às discriminações pelas quais eles passavam, às perturbações decorrentes das doenças e à precariedade socioeconômica, constituíam verdadeiramente atentados aos direitos humanos. Assim, a procura do auxílio médico, quando se está em situação irregular no país, podia acentuar os sentimentos de medo e insegurança, acentuando ainda mais as perturbações causadas pelas doenças.

Apesar de avanços, como a lei Aide Médicale État Renovée (AMER), que beneficiava imigrantes sans papier, o conhecimento e a reivindicação de acesso aos serviços de saúde continuavam sendo problemáticos. Por outro lado, a esperança de que a obtenção da AMER tornasse mais fácil a obtenção de um visto de estada, que terminava por encorajar a vinda de novos imigrantes, mostrou como essa lei pode contribuir para a produção da clandestinidade ${ }^{28}$. Nesse sentido, o fato de essa lei garantir auxílio médico somente aos estrangeiros que desejassem permanecer na França excluía parte do contingente de estrangeiros que vinham à França exclusivamente para se tratar pela impossibilidade de assistência em seus países de origem, muitos desses, colônias exploradas pela França. Enfim, tratava-se de medidas paliativas e que não aportavam mudança real na situação dessa população.

Médecins du Monde assume a função do Estado, quando o tratamento não é assegurado pelo sistema comum de saúde. O centro MDM em Paris, concebido para ser provisório, existe até hoje, e é importante perguntar sobre seu papel real atualmente. Ele auxilia na inclusão desses indivíduos ou é somente uma ajuda pontual de acolhimento e cuidados médicos? Qual é o impacto que ele tem nos usuários e voluntários? Por meio da elaboração da etnografia da interação entre esses usuários e voluntários, meu objetivo foi mostrar como essas relações se desenvolveram. A leitura que proponho aqui para essas situações é que elas são parte de experiências culturais e sociais inscritas em um contexto global da sociedade francesa. A análise dessas interações permite compreender como se reproduzem no microssocial relações de acolhimento e aceitação, mas também de conflitos e rejeição.

Do ponto de vista dos usuários, a maior parte vinha ao centro buscando tratamento médico e utilizava a estrutura de maneira utilitária e pragmática. O

\footnotetext{
${ }^{28} \mathrm{O}$ termo clandestino e clandestinidade foi muito usado na França nesse período, e, estudos, mostram como a produção de políticas produzia essa situação de "clandestinidade" com todos os sentimentos e valores negativos que o circundam (cf. FERREIRA, Jaqueline. Do estrangeiro ao excluído: formas contemporâneas de classificação dos imigrantes africanos em uma organização humanitária francesa; FASSIN, MORRICE, op. cit.).
} 
centro os acolhia, porém, sempre insistindo que realizassem os procedimentos para obter os direitos de acesso aos dispositivos comuns da França. Outros buscavam o centro para resolver sua situação de irregularidade administrativa quanto ao visto de estadia, o que poucas vezes era possível. Os voluntários usavam correntemente a expressão "não se pode lhes dar muita esperança", o que resumia seus sentimentos de impotência e frustração em relação à situação dos usuários do centro. Eles não acreditavam muito na possibilidade de inclusão social desses indivíduos, mas, apesar de todos os obstáculos, eles empregavam esforços e procuravam dar formas de legitimidade a um trabalho que muitas vezes não aportava uma ajuda concreta aos usuários. Todavia, o trabalho adquiria sentido diante da possibilidade de estabelecer vínculos com esses usuários, evidenciando uma relação de confiança e o reconhecimento da ajuda prestada por eles. Da mesma forma, não se pode negligenciar o reconhecimento social que aportava o engajamento em uma organização humanitária para os franceses.

As relações de alteridade eram inerentes à interação entre usuários e voluntários. Essas relações de alteridade estavam marcadas por diferenças de natureza e grau, em que categorias sociais e culturais eram confundidas, pois, se de um lado havia uma diversidade de nacionalidades, etnias e culturas, igualmente, estabeleciam-se relações entre diferentes classes sociais. Essas alteridades diversas se refletiam nos elementos estruturais da relação entre nacionais e imigrantes, voluntários e usuários, ricos e pobres. No entanto, os voluntários franceses tentavam afastar esse estranhamento, mediante uma prática de respeito à cultura e à situação de precariedade dos usuários, procurando estabelecer uma relação próxima com eles, de acordo com a assistência humanitária ideal.

As várias situações observadas mostraram igualmente que as aflições dos usuários não se restringiam ao físico, mas revelavam sofrimento também moral e que se perpetuava no tempo. Explicitando suas dificuldades, esses indivíduos mostravam as experiências relativas a um quotidiano de insegurança, medo, precariedade. Concluindo, é importante reconhecer que a dificuldade que o centro encontrava na realização de um trabalho de inclusão dos usuários relativizava o papel proposto pela organização Médecins du Monde. Todavia, não se trata de negar a importância dessas intervenções. Suprimir esses serviços implicaria privar um número importante de indivíduos de acolhimento e cuidados em saúde. Acima de tudo, o papel dos voluntários consistia mais em reparar do que em tratar, ou seja, o verdadeiro trabalho realizado pelos voluntários do centro é um trabalho não mensurável, invisível, cotidiano: um trabalho de reparação física e moral.

\section{Bibliografia}

ASTIER, Isabelle. Se raconteur aux Autres. Sciences Humaines, v. 7, n.184, 2007, p. 5-6. 
BARCELLOS REZANDE, Cláudia; PEREIRA COELHO, Maria Cláudia. Antropologia das emoções. Rio de Janeiro: Editora FGV, 2010.

CENTLIVRES, Pierre; CENTLIVRES-DEMONT, Micheline. L'anthropologie face à I'humanitaire. État, Islam et Tribus face aux organisations internationales. Le cas de l'Afghanistan 1978-1998. Annales, v. 54, 1999, p. 945-965.

DAUVIN, Pascal; SIMÉANT, Johanna. Le travail humanitaire. Les acteurs des ONG, du siège au terrain. Paris: Presses de Sciences Po, 2002.

FAINZANG, Sylvie. La Relation médecins/malades: information et mensonge. Paris: Presses universitaires de France, 2006.

FASSIN, Didier; MORICE, Alain. Les épreuves de l'irrégularité: les sans-papiers; entre déni d'existence et reconquête d'un statut. In SCHNAPPER, Dominique (org.). Exclusions au coeur de la cité. Paris: Économisa, 2001, p. 261-309.

FASSIN, Didier. La Raison Humanitaire: une histoire morale du temps present. Paris: Ed. EHESS, Galimard-Seuil, 2010.

FASSIN, Didier; PANDOLFI, Mariella. Contemporary States of Emergency. The politics of military and humanitarian interventions. New York: Zone Books; Cambridge, Mass, 2010.

FERREIRA, Jaqueline. Soigner les Mal Soignés, Ethnologie d'un centre de soins gratuits. Paris: Editora L'Harmattan, 2004.

FERREIRA, Jaqueline. O Humanitário: uma história de ideologias e práticas face às populações vulneráveis. Saúde e Direitos Humanos, v. 4, 2008, p. 1-5.

FERREIRA, Jaqueline. O Humanitário no Brasil: entre o ideal universal e a cultura local. In FERREIRA, Jaqueline; $\mathrm{SCHUCH}$, Patrice. (orgs.). Direitos Humanos e Ajuda Humanitária: perspectivas sobre família, gênero e saúde. Rio de Janeiro: Fiocruz, 2010, p.49-76.

FERREIRA, Jaqueline. Tratar, Cuidar: valores e práticas terapêuticas na assistência humanitária ao sans domicile fixe. Antropolítica (UFF), v. 29, 2010, p. 79-97.

FERREIRA, Jaqueline. A Consulta Médica como Drama Social - um olhar etnográfico. Cadernos Saúde Coletiva, UFRJ, v. XIX, 2011, p. 215-224.

FERREIRA, Jaqueline. Do estrangeiro ao excluído: formas contemporâneas de classificação dos imigrantes africanos em uma organização humanitária francesa. Anthropológicas (UFPE), v. 22, n. 2, 2011, p. 61-81.

FOUCAULT, Michel. Microfísica do Poder. Rio de Janeiro: Graal, 1985.

GEREMEK, Bronislaw. Os filhos de Caim. Vagabundos e miseráveis na literature europeia (1400-1700). São Paulo: Cia. das Letras, 2011.

GOFFMAN, Erving. Apresentação de si. In A Representação do Eu na Vida Cotidiana. Rio de Janeiro: Vozes, 1985.

GOFFMAN, Erving. La Présentation de Soi. In La Mise en scène de la vie quotidienne. Paris: Ed. Minuit, 1973.

GROSJEAN, Michèle; LACOSTE, Michèle. L'oral et l'écrit dans les communications de travail ou les illusions du tout écrit. Sociologie du travail, n. 4, 1998, p. 439-461.

KOUCHNER, Bernard. L'Ile de Lumière. Paris: Ramsay, 1980. 
LENOIR, René. Les exclus. Un Français sur dix. Paris: Seuil, 1974.

MESSU, Michel. Pauvreté et Exclusion en France. In MERRIEN, François-Xavier (dir.). Face à la Pauvreté. Paris: Ed. de L'Atelier/ed. Ouviréres, 1994.

MESTIRI, Ezzedine. Au Dispensaire de Médecins du Monde à Paris. Hommes et Immigrations, v. 1101, 1987, p. 58-61.

MAMOU, Jacky. Entre action humanitaire et solidarité citoyenne: I'exemple de la Mission France de Médecins du Monde. In LEBAS, Jacques; CHAUVIN, Pierre (orgs.). Précarité et Santé. Paris: LAVOISIER MSP, 1998.

OLIVIER DE SARDAN, Jean-Pierre. La Politique du Terrain. Enquête, n. 1, 1995, p. 71-109.

PARIZOT, Isabelle. Soigner les exclus. Identités et rapports sociaux dans les centres de soins gratuits. Paris: Presses Universitaires de France, 2003.

PARIZOT, Isabelle; CHAUVIN, Pierre; PAUGAM, Serge. The Moral Career of Poor Patients in Free Clinics. Social Science \& Medicine, v. 61, 2005, p. 1369-1380.

ROSANVALLON, Pierre. La Crise de l'État Providence. Paris: Seuil, 1981.

RUFFIN, Jean-Christophe. Le Pitiè Humanitaire. Paris: Hachette Pluriel, 1986.

SAILLANT, Francine. A Responsabilidade na Intervenção Humanitária: indiferença ou engajamento? In FERREIRA, Jaqueline; $\mathrm{SCHUCH}$, Patrice (orgs.). Direitos Humanos e Ajuda Humanitária: perspectivas sobre família, gênero e saúde. Rio de Janeiro: Fiocruz, 2010.

SAYAD, Abdelmalek. La double absence: des illusions de l'immigré aux souffrances de l'immigré. Paris: Seuil, 1999.

SMITH, Adam. Théorie des sentiments moraux. Paris: Ed'Aujourd'hui, 1960.

\section{Documentos MDM}

Rapport d'activité de la Mission France. 2000.

GOURIOU, J. Rapport d'Enquete sur la Mission France. Dec., 1993.

PAUGAM, Serge; PARIZOT, Isabelle; DAMON, Julien; FIRDION, Jean-Marie. La relation humanitaire. La mission France de médecins du monde à Paris. In Rapport Médecins du Monde. Janvier, 1997.

Recebido para publicação em 04.02.2016

Aceito para publicação em 10.05.2016

Received for publication in February 04 ${ }^{\text {th }}, 2016$

Accepted for publication in May $10^{\text {th }}, 2016$

ISSN impresso 1980-8585

ISSN eletrônico 2237-9843

http://dx.doi.org/10.1590/1980-85852503880005109 